\title{
IBM HIMPUNAN PENDIDIKAN ANAK USIA DINI KOTA SEMARANG
}

\author{
Juli Ratnawati', Imam Nuryanto², Eko Hari Rachmawanto ${ }^{3}$, Kusni Ingsih ${ }^{4}$ \\ Jl. Nakula I No. 5-11 Semarang, 50131 \\ Telp. (024) 3517261, Faks. (024) 3569684 \\ E-mail: ratnawatijuli74@gmail.com ${ }^{1}$, Imam.nuryanto@dsn.dinus.ac.id ${ }^{2}$, \\ rachmawanto@ research.dinus.ac.id ${ }^{3}$.kusni@dosen.dinus.ac.id ${ }^{4}$
}

\begin{abstract}
Abstrak
Pendidikan Anak Usia Dini di Kota Semarang telah mengalami kemajuan yang cukup menggembirakan. Hal ini terbukti dengan semakin banyaknya jumlah lembaga PAUD yang bermunculan dalam rangka memberikan pelayanan pendidikan anak usia dini kepada masyarakat.

Himpunan Pendidik Anak Usia Dini (HIMPAUDI) Kota Semarang mempunyai komitmen yang terwujudkan dalam program kerjanya untuk dapat memajukan pendidikan anak usia dini pada umumnya dan meningkatkan profesionalitas pendidik PAUD pada khususnya. Akan tetapi dalam pelaksaan tugas sebagai pendidik, mereka ternyata memiliki kendala dalam penguasaan penggunaan komputer. Pendidik PAUD di Kota Semarang yang masih berpendidikan SMA dan Sarjana S1 banyak yang belum menguasai penggunaan komputer untuk menunjang pekerjaan mereka sehari hari.

Tujuan dari Pengabdian ini adalah memberi kompetensi para pendidik PAUD untuk menguasai teknologi komputer agar dapat membantu pekerjaan mereka baik dalam administrasi maupun dalam pengajaran kepada anak didik PAUD. Target dari pengabdian ini adalah terciptanya peningkatan kompetensi penguasaan para guru PAUD.
\end{abstract}

Kata kunci: PAUD, pelatihan, komputer

\section{PENDAHULUAN}

Teknologi informasi (TI) memiliki potensi untuk mengubah sarana yang kita pelajari dan mengakses informasi dalam dua cara penting. Pertama, IT memungkinkan kami melakukan banyak hal yang sudah kami lakukan dengan lebih cepat, lebih fleksibel, lebih efisien dan dengan akses yang lebih luas untuk semua. Kedua, IT memungkinkan kita untuk melakukan hal-hal yang tidak dapat kita lakukan sekarang, atau melakukannya dengan cara yang sangat berbeda. TI memungkinkan lingkungan dan pengalaman pembelajaran yang benar-benar baru yang melampaui ruang kelas, kurikulum, dan format berbasis teks di mana kita terbiasa [1].

Rusman [2] menyatakan bagi para pendidik, aplikasi MS Office merupakan aplikasi yang sangat erat hubungannya dengan aktifitas mereka dalam mengerjakan tugas kependidikan seharihari. Aplikasi ini sangat membantu dalam mempersiapkan kegiatan pembelajaran, mengajar, mengevaluasi dan menyiapkan laporan akhir pembelajaran [3]. Penggunaan MS Office ini akan 
sangat menunjang pekerjaan para pendidik apabila digunakan secara optimal sesuai dengan menu-menu yang disediakan [4].

Webb et al berpendapat Internet juga menjadi alat instruksional yang penting untuk memfasilitasi transfer berbagai jenis informasi dari satu komputer ke komputer lain, dan dengan cepat menjadi sarana komunikasi yang efektif di sekolah. Instruksi berbasis internet telah dimanifestasikan dalam satu-ke-satu (tutor-ke-siswa), satu-ke-banyak (tutor-ke-kelompok) dan banyak-banyak (kelompok-ke-kelompok) mendekati instruksi [5]. Sehingga dapat dikatakan bahwa internet mampu digunakan dalam proses pedidikan di sekolah, terutama sebagai layanan dalam pembelajaran. Teknologi yang tersedia dapat dimanfaatkan oleh guru yang mengajar dengan menggunakan akses internet. sehingga terciptalah pendidikan interaktif antara guru dan murid yang kelanjutannya mempu berkontribusi dalam penemuan sumber informasi terbaru.

Pendidikan Anak Usia Dini (PAUD) sebagai upaya untuk menciptakan sumber daya manusia yang bermutu merupakan tahapan yang sangat strategis yang dilakukan secara bertahap,sistematis dan menjadi tanggung jawab Pemerintah,masyarakat dan dunia usaha lainnya. PAUD memegang peranan penting dan menentukan bagi sejarah perkembangan anak selanjutnya,sebab merupakan fondasi dasar bagi kepribadian anak.

Seiring berkembangnya jumlah PAUD di kota Semarang,telah dibentuk himpunan khusus untuk pengelolaan lembaga yang bernama HIMPAUDI. HIMPAUDI Kota Semarang dibentuk pada tahun 2005 oleh para pengurus lembaga yang bertujuan untuk mempermudah interaksi seluruh anggota PAUD sekota Semarang. Berinteraksi dengan lingkungan merupakan salah satu fitrah manusia,sebagai individu serta makhluk sosial.Sekecil apapun kebutuhan yang mereka perlukan tetap membutuhkan orang lain. Para pendidik PAUD dalam proses belajar mengajarnya telah menggunakan aplikasi berbasis MS Office dan Internet, hanya dalam penggunaannya mereka merasa belum optimal sehingga belum mampu menunjang prestasi dan kinerja mereka.

\section{METODE PELAKSANAAN}

\section{Analisis Masalah}

Adapun permasalahan khusus yang dihadapi para pendidik PAUD yang tergabung dalam HIMPAUDI adalah sebagai berikut : 
a. Para pendidik PAUD belum mampu mengoperasikan program komputer Microsoft Office untuk membantu pekerjaan administrasi mereka

b. Para pendidik PAUD belum mampu mengoperasikan internet untuk mendukung kemampuan mereka dalam berkomunikasi dengan sesama pengelola PAUD se Indonesia.

\subsection{Solusi Yang Ditawarkan}

Berdasarkan justifikasi permasalahan yang dihadapi oleh mitra maka tim pelaksana pengabdian masyarakat akan melaksanakan pendampingan berupa pelatihan bagaimana mengoperasikan Microsoft Office dan Internet yang oprimal bagi pendidik PAUD dan memberikan pendampingan dengan cara konsultsi apabila mereka mengalami kendala dalam penggunaan program tersebut sehari-hari.

Tabel 3.1 : Metode Pemecahan Masalah Yang Dihadapi Mitra

\begin{tabular}{|l|}
\hline Masalah yang harus ditangani \\
\hline Belum menguasai Microsoft Office \\
\hline Belum menguasai internet \\
\hline
\end{tabular}

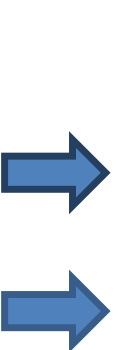

Pemecahan masalah yang ditawarkan

Pengenalan dan aplikasi penggunaan Microsoft Office

Pengenalan dan aplikasi penggunaan internet untuk membantu berkomunikasi

\section{HASIL DAN PEMBAHASAN}

Adapun realisasi dari target output dan capaian pengabdian masyarakat dapat disimpulkan sebagai berikut:

Tabel 3.1 Capaian Pelaksanaan Pengabdian Masyarakat

\begin{tabular}{|l|l|l|c|}
\hline No & \multicolumn{1}{|c|}{ Tahap } & \multicolumn{1}{|c|}{ Output } & Capaian \\
\hline 1 & Persiapan & Power point MS & $100 \%$ \\
& Menyiapkan materi pelatihan & Word, MS & \\
& dan peralatan yang akan & Excell, MS & \\
& dipakai & Power point, & \\
& & Animasi dan & \\
& & Internet & \\
\hline
\end{tabular}




\begin{tabular}{|l|l|l|l|}
\hline 2 & $\begin{array}{l}\text { Pelaksanaan } \\
\text { Pelatihan diberikan dengan } \\
\text { memberikan teori dan } \\
\text { praktik MS Office dan } \\
\text { Internet }\end{array}$ & $\begin{array}{l}\text { Peserta } \\
\text { mendapatkan } \\
\text { pengetahuan } \\
\text { tentang } \\
\text { Office MS dan } \\
\text { internet }\end{array}$ \\
\hline 3 & $\begin{array}{l}\text { Pendampingan } \\
\text { Pendampingan dilakukan } \\
\text { dengan konsultasi dan } \\
\text { diskusi bila menemui } \\
\text { kesulitan atas materi yang } \\
\text { telah disampikan }\end{array}$ & $\begin{array}{l}\text { Peserta } \\
\text { memahami } \\
\text { penggunaan MS } \\
\text { Office dan } \\
\text { internet secara } \\
\text { optimal untuk } \\
\text { menunjang } \\
\text { kinerja }\end{array}$ \\
\hline
\end{tabular}

\section{KESIMPULAN}

Pengabdian masyarakat ini bermanfaat bagi pendidik PAUD dengan memberikan luaran berupa kemampuan membuat naskah, surat menyurat, menyusun laporan keuangan, menghitung dengan memakai rumus, membuat tabel pelaporan kinerja PAUD, menyusun slide presentasi yang disisipi dengan animasi serta membuat video sederhana dengan menggunakan animasi dan membuat email.

\section{DAFTAR PUSTAKA}

[1] Roca, et.al. 2006. Understanding e-learning continuance intention: An Extension of the Technology Acceptance Model. International Journal Human-Computer Studies, 64, 683-696.

[2] Rusman. 2012.Belajar dan Pembelajaran Berbasis Komputer. Bandung: Alfa Beta.

[3] Kurniawan, A. 2007. MS Office Powe Point 2007, Bandung : P.T. Pradnya Paramita.

[4] Tosin, Rijanto dan Ramona, Valentzia. 2000, Microsoft Office 2000, DINASTINDO, Jakarta

[5] Agboola, Abdulhameed Kayode. 2006. Assessing Awareness and Peceptions of Academic Staff in Using E-Learning Tools for Instructional Delivery in a Post-Secondary Institution: A Case Study. The Innovation Journal: The Public Sector Innovation Journal, Volume 11 (3), article 4. Diakses dari http://www.innovation.cc/scholarly-style/agboola4k.pdf pada 13 Maret 2018. 